\title{
Effects of absorptive capacity, trust and information systems on
}

\section{product innovation}

\begin{abstract}
Purpose This study aims to empirically investigate the mechanisms through which absorptive capacity (AC), trust and information systems jointly influence product innovation.
\end{abstract}

Design/methodology/approach This study proposes a research model to examine the mediating role of $\mathrm{AC}$ on the impacts of trust and information systems on product innovation and the moderating roles of trust and information systems on the relationship between $\mathrm{AC}$ and product innovation. The hypotheses are empirically tested using regression and bootstrapping methods and data collected from 276 manufacturing firms in China.

Findings This study finds that trust and information systems positively affect product innovation and the effects are fully mediated by AC. AC also significantly enhances product innovation and the effect is amplified by trust as well as information systems. In addition, the results show that trust and information systems improve AC both individually and interactively.

Originality/value The findings extend existing knowledge on the antecedents of AC and the contingent conditions under which a manufacturer's AC is more effective than that of its rivals. The results also clarify the mechanisms through which trust and information systems improve product innovation. This study provides insights into the complex relationships among a manufacturer's sociotechnical systems, knowledge management processes and new product development, and reveals how to design organisational systems to fully capitalise the value of AC on product innovation.

Keywords: absorptive capacity; product innovation; trust; information systems 


\section{Introduction}

Absorptive capacity (AC) serves as an important component of a manufacturer's learning capabilities by creating a set of organisational routines and processes (Cohen and Levinthal, 1990, Zahra and George, 2002). It can help a manufacturer develop new knowledge as well as adapt existing knowledge into new applications (Lane et al., 2006, Lawson and Potter, 2012, Nagati and Rebolledo, 2012, Whitehead et al., 2016). Researchers report that AC is positively associated with a manufacturer's performance and capabilities (Tu et al., 2006, Francalanci and Morabito, 2008, Kauppi et al., 2013, Tavani et al., 2014, Iyengar et al., 2015), including product innovation (Cepeda-Carrion et al., 2012, Ritala and Hurmelinna-Laukkanen, 2013, Saenz et al., 2014). Both mediation (Francalanci and Morabito, 2008, Cepeda-Carrion et al., 2012, Setia and Patel, 2013, Saenz et al., 2014, Iyengar et al., 2015) and moderation (Patel et al., 2012, Kauppi et al., 2013, Ritala and Hurmelinna-Laukkanen, 2013, Tavani et al., 2014) models have been used to empirically investigate the relationships between AC and performance outcomes. However, the contingent conditions that influence AC's effect on product innovation have been overlooked in previous research.

Sociotechnical systems theory proposes that a firm is composed of both social and technical systems (Pasmore, 1988). They should be treated as interdependent aspects of an organisation and be jointly designed according to internal and external environments (Pasmore, 1988, Huber and Brown, 1991). Trust and information systems reflect the social and technical aspects of an organisational system (Mayer et al., 1995, Alavi and Leidner, 2001). An organisational design that only considers one of the two aspects will be inefficient for knowledge absorption and product innovation (Huber and Brown, 1991, Lane et al., 2006). In addition, a knowledge-based view of the firm argues that firms can gain competitive advantages by combining and creating tacit and explicit knowledge and 
they have different properties and require different mechanisms for absorption (Nonaka, 1994, Zhang et al., 2015). Trust and information systems provide two mechanisms governing the flows and applications of tacit and explicit knowledge respectively (Malhotra et al., 2005, Nahapiet and Ghoshal, 1998, Roberts et al., 2012). Trust enables employees to access each other's private experiences and build a social system for them to share know-how, facilitating the socialisation and externalisation of tacit knowledge (Nonaka, 1994). Trust also motivates cooperative behaviour and reduces opportunism in cross-functional collaboration, which promote joint learning (Yeung et al., 2009, Zahra and George, 2002). Information systems facilitate a firm to analyse, distribute and record large amount of information quickly and efficiently and hence provide a technical system to combine and internalise explicit knowledge (Nonaka, 1994, Setia and Patel, 2013).

Researchers argue that social integration mechanisms can build connectedness and shared meaning among employees which facilitate the free flow of knowledge (Zahra and George, 2002, Todorova and Durisin, 2007) and that the synergies between information technologies and AC affect firm performance (Roberts et al., 2012). However, there is a lack of explanation of how trust and information systems jointly affect knowledge absorption and how they influence the effects of AC remains under-addressed (Hotho et al., 2012, Marabelli and Newell, 2014, Iyengar et al., 2015). In addition, Volberda et al. (2010) argue that organisational design has been relatively neglected in the AC literature. Moreover, few if any researchers have linked AC to the effects of trust and information systems on product innovation (Cepeda-Carrion et al., 2012, Setia and Patel, 2013).

The objective of this study is to empirically investigate the mechanisms through which AC, trust and information systems jointly influence product innovation. This study addresses two research questions. First, does AC mediate trust and information systems' 
effects on product innovation? Second, do trust and information systems moderate AC's effect on product innovation?

\section{Theoretical background and research hypotheses}

\subsection{Absorptive capacity}

AC can be defined as a firm's "ability to recognize the value of new information, assimilate it, and apply it to commercial ends" (Cohen and Levinthal, 1990:128). Researchers argue that $\mathrm{AC}$ is a multiple-dimensional concept and the components are interrelated (Zahra and George, 2002, Zhang et al., 2015). Research and development (R\&D) intensity, R\&D investment and patent have been used as proxies for measuring a firm's AC. However, such proxies are unidimensional measures that are not able to fully gauge this multi-dimensional construct (Roberts et al., 2012, Volberda et al., 2010) and cannot capture a firm's learning processes (Setia and Patel, 2013). In addition, they only focus on technological knowledge whereas neglect or undervalue market knowledge (Lane et al., 2006, Ritala and Hurmelinna-Laukkanen, 2013). With a few exceptions (e.g. Patel et al., 2012, Saenz et al., 2014, Zhang et al., 2015), empirical operations management studies measure AC using prior related knowledge and communication routines (Tu et al., 2006, Nagati and Rebolledo, 2012, Kauppi et al., 2013, Tavani et al., 2014) or general scales related to organisational learning (Zacharia et al., 2011, Whitehead et al., 2016). However, they do not directly capture a firm's capability to implement and apply knowledge (Lane et al., 2006, Roberts et al., 2012) nor reflect the richness of the construct (Volberda et al., 2010).

This study conceptualises AC as three components (i.e. acquisition, assimilation and application) that are necessary for a manufacturer to absorb knowledge from supply chains (Nagati and Rebolledo, 2012, Zhang et al., 2015). Acquisition refers to a 
manufacturer's ability to identify and obtain knowledge that is critical to its operations from suppliers and customers (Hult et al., 2004, Todorova and Durisin, 2007). Suppliers and customers are important sources of technological and market knowledge, such as new product concepts, local customers' special demands and new applications of materials (Hult et al., 2006). A manufacturer can acquire knowledge from supply chain partners through special procedures and interactions, such as meetings or surveys (Hult et al., 2004). Assimilation refers to a manufacturer's processes and routines for analysing, interpreting and understanding externally acquired knowledge and combining it with internal knowledge (Zahra and George, 2002). Various practices, such as group learning, collaborative problem solving, knowledge sharing routines and training programs, can be used to assimilate knowledge (Hult et al., 2004, Jansen et al., 2005). Application refers to the processes through which a manufacturer exploits knowledge to improve and expand its daily operations, create commercial outputs and predict future trends (Lane et al., 2006, Zahra and George, 2002). A manufacturer can apply knowledge by implementing employees' suggestions and ideas and reviewing long-term forecasting to discover business opportunities (Volberda et al., 2010). Hence, such conceptualisation provides a thorough assessment of both external-facing and internal components of AC (Todorova and Durisin, 2007, Roberts et al., 2012, Zhang et al. 2015).

Researchers find that AC positively influences knowledge transfer (Lawson and Potter, 2012, Whitehead et al., 2016), innovation (Cepeda-Carrion et al., 2012, Ritala and Hurmelinna-Laukkanen, 2013), manufacturing capabilities (Tu et al., 2006, Zhang et al., 2015) and business performance (Francalanci and Morabito, 2008, Nagati and Rebolledo, 2012). In addition, empirical evidence exists that AC mediates the relationships between information systems and business performance (Francalanci and Morabito, 2008, Liu et al., 2013, Setia and Patel, 2013, Iyengar et al., 2015) and between organisational 
compatibility and innovation (Saenz et al., 2014). Researchers also report that AC positively moderates the relationships between manufacturing flexibility and firm performance (Patel et al., 2012), between E-purchasing tools and category performance (Kauppi et al., 2013) and between supplier involvement and agile product innovation (Tavani et al., 2014); and that the effect of AC is moderated by environmental conditions such as complexity (Setia et al., 2013), uncertainty (Saenz et al., 2014) and appropriability regime (Ritala and Hurmelinna-Laukkanen, 2013). However, there is a lack of empirical studies on how AC interacts with a manufacturer's organisational system in influencing product innovation.

\subsection{Product innovation}

Product innovation refers to the new applications of knowledge and skills that can change what a manufacturer offers to customers (Kim et al., 2012). A manufacturer can develop incremental or radical product innovations, which are different in the degree of newness as perceived by customers (Damanpour, 2010, Ritala and HurmelinnaLaukkanen, 2013). Radical innovations fundamentally change a manufacturer's technological trajectory and target emerging customers, whereas incremental innovations result in small changes in a manufacturer's technological capabilities and address existing customer needs (Kim et al., 2012, Enkel et al., 2017). Hence, radical and incremental innovations are associated with exploratory and exploitative learning respectively (Enkel et al., 2017). Exploration involves a conscious effort to move away from current organisational routines and knowledge bases, whereas exploitation focuses on using the knowledge that is closely related to firms' existing knowledge bases (Katila and Ahuja, 2002). New product development is determined by the combination of exploration and exploitation (Katila and Ahuja, 2002). Manufacturers can create new products by integrating existing knowledge and adapting existing products and technologies 
innovatively to fit new environments (Hargadon and Sutton, 1997). New products can also be developed by using new components or modules that overturn the core design concepts of current products (Hargadon and Sutton, 2000). Product innovation requires manufacturers to identify potential new markets and valuable business opportunities, recognise and obtain new technological and market knowledge from environments and transform and integrate such knowledge into internal operations quickly (Hult et al., 2004, Whitehead et al., 2016). Hence, manufacturers' capabilities to absorb and leverage both codified explicit and experience-based tacit knowledge, some of which may reside in supply chains, play a critical role in new product development (Hargadon and Sutton, 1997; Wang et al., 2011). AC enables a manufacturer to conduct exploratory and exploitative learning simultaneously (Marabelli and Newell, 2014, Enkel et al., 2017). In particular, acquisition allows a manufacturer to recognise and obtain valuable knowledge from supply chains through exploratory learning, and application enables the manufacturer to use assimilated knowledge to create new knowledge and commercial outputs through exploitative learning (Lane et al., 2006). Hence, AC can affect both radical and incremental innovation (Ritala and Hurmelinna-Laukkanen, 2013, Enkel et al., 2017). In addition, researchers argue that product innovation may be influenced by a manufacturer's demographic characteristics such as size and industry (Damanpour, 2010, Mazzola et al., 2015a) and R\&D collaboration with external partners (Hargadon and Sutton, 2000, Un et al., 2010, Lawson and Potter, 2012, Mazzola et al., 2015b; Wang et al., 2011).

\subsection{Trust and information systems}

Trust can be defined as the "willingness of a party to be vulnerable to the actions of another party based on the expectation that the other will perform a particular action important to the trustor, irrespective of the ability to monitor or control that other party" 
(Mayer et al., 1995:712). This study focuses on the trust among employees in marketing, production and $R \& D$ departments as it facilitates social interactions within a manufacturer (Hotho et al., 2012). High levels of trust indicate that both "teacher" and "student" are reliable, benevolent and honest (Mayer et al., 1995). Trust encourages the "teacher" to actively help the "student" understand the knowledge he/she is offering. The "student" will also have a positive expectation of the "teacher", which increases the willingness of the "student" to absorb knowledge (Mayer et al., 1995, Nahapiet and Ghoshal, 1998). Trust thus creates a sense of security among employees that their knowledge will not be exploited by colleagues beyond what is intended. It provides a social system that is critical for tacit knowledge transfer and creation (Wang et al., 2011). The collaboration among marketing, production and R\&D departments plays a critical role in new product development (Calantone et al., 2002, Swink and Song, 2007). Employees in different functions may have diverse perspectives and motivations and different experiences and backgrounds, which may become barriers for cross-functional product development (Swink and Song, 2007). Trust among R\&D, production and marketing departments can not only lead to a working environment with open communication and team spirit but also generate reciprocity and solidarity, which reduce the costs and lead times for collaborative knowledge management and innovation (Adler and Kwon, 2002).

Information systems offer effective tools for employees to scan environments and manage knowledge (Alavi and Leidner, 2001, Tu et al., 2006). By using common specifications or formats for information exchange and knowledge transfer, information systems help a manufacturer collect codified facts from environments quickly with low costs (Tavani et al., 2014). They assist a manufacturer in analysing and assigning meaning to obtained information (Malhotra et al., 2005). Information systems also automate and 
routinize information assimilation, distribution and storage, which improve a manufacturer's information processing capability (Alavi and Leidner, 2001, Francalanci and Morabito, 2008). They can link internal and external sources of information to improve the breadth and depth of information flows and provide effective search and retrieval mechanisms for locating relevant information (Liu et al., 2013). As a result, information systems form a technical system that facilitates knowledge absorption, especially for explicit knowledge (Malhotra et al., 2005, Setia and Patel, 2013). Current knowledge on how information systems and AC jointly affect performance remains unclear (Liu et al., 2013, Iyengar et al., 2015). For example, empirical evidence exists that information systems mediate (Cepeda-Carrion et al., 2012) or moderate (Setia and Patel, 2013) the relationships between $\mathrm{AC}$ components, and that $\mathrm{AC}$ mediates (Francalanci and Morabito, 2008, Liu et al., 2013, Iyengar et al., 2015) or moderates (Kauppi et al., 2013) the impacts of information systems on performance.

\subsection{Research hypotheses}

Knowledge is a strategic resource and the capabilities in knowledge absorption and development have persisting effects on innovation (Hult et al., 2006, Lane et al., 2006). Trust among employees enhances product innovation by facilitating cooperation and collaboration among marketing, production and R\&D departments (Swink and Song, 2007). Information systems provide a platform and tools that facilitate employees to process information and make decisions related to new product development quickly (Liu et al., 2013). It is the new knowledge and new applications of existing knowledge developed through cross-functional collaboration and by using information systems that lead to product innovation (Nonaka, 1994, Nahapiet and Ghoshal, 1998). Hence, this study argues that AC, which enables a manufacturer to acquire and implement knowledge, mediates the effects of trust and information systems on product innovation. In addition, 
explicit knowledge can be transferred and exploited using systematic and standard procedures and tools, whereas the sharing and implementation of tacit knowledge requires social interactions and relationships among employees (Nonaka, 1994). Hence, this study argues that trust and information systems can form sociotechnical systems that positively moderate AC's effect on new product development. Because the interactions between tacit and explicit knowledge improve knowledge creation capability (Nonaka, 1994), we propose that trust and information systems are complementary in improving AC. The proposed conceptual framework is presented in Figure 1.

Figure 1 about here

Manufacturers can create new products by brokering external knowledge and developing new applications of existing knowledge (Hargadon and Sutton, 2000, Zhang et al., 2016). R\&D employees must work together with marketing and production employees who can provide knowledge about customer preferences and production processes to guarantee the marketability and manufacturability of new product designs (Swink and Song, 2007). High levels of trust indicate that employees have beliefs in the good intention, reliability and openness among each other (Nahapiet and Ghoshal, 1998, Adler and Kwon, 2002). Hence, trust among marketing, production and R\&D employees can facilitate cross-functional product development (Calantone et al., 2002). Employees can hence grasp what changes on product concepts, components and linkages between them really matter for customers and understand the capacity and capability of the manufacturing processes, improving product innovation (Calantone et al., 2002, Kim et al., 2012).

Trust increases employees' confidence about colleagues' goodwill and their willingness for participating in social interactions, which lead to common understandings among employees (Adler and Kwon, 2002, Mayer et al., 1995). Hence, trust improves the 
quality, relevance and timeliness of knowledge flows and facilitates cooperation and collaboration among employees (Wang et al., 2011). Employees from different departments can develop common goals, objectives and codes of communication when interacting with suppliers and customers, improving acquisition (Hult et al., 2004). Trust also helps employees collaborate on exchanging and combining acquired knowledge (Nahapiet and Ghoshal, 1998), improving assimilation and application (Jansen et al., 2005, Volberda et al., 2010). Therefore, trust plays a key role in facilitating the development of AC (Marabelli and Newell, 2014). However, close interpersonal relationships alone cannot yield new products. It is the new technological and market knowledge that leads to product innovation (Hult et al., 2006, Zacharia et al., 2011). AC enables a manufacturer to obtain external knowledge, combine and integrate it with existing knowledge and incorporate new knowledge into product designs (Zhang et al., 2015). In particular, acquisition facilitates employees to identify and obtain knowledge regarding markets and product components from customers and suppliers (Lane et al., 2006, Volberda et al., 2010). Assimilation assists employees in analysing and processing acquired knowledge together, which lead to a shared understanding on the impact of the changes in customer preferences on product designs (Hult et al., 2004). Application enables employees to creatively redesign components and product architecture and reconfigure production processes accordingly, helping a manufacturer commercialise knowledge (Zahra and George, 2002). The three components of AC jointly provide a mechanism for employees to leverage knowledge to design new products. Therefore, the following hypothesis is proposed.

\section{H1: AC mediates trust's effect on product innovation.}

Information systems provide superior capabilities to communicate with customers and suppliers, support information processing and develop organisational memory 
(Roberts et al., 2012, Tu et al., 2006), enabling manufacturers to apply past experiences and learned skills to develop new products (Liu et al., 2013). They facilitate a manufacturer to collaborate with external partners across geographic boundaries on a virtual platform, which helps employees reach more suppliers and customers, incorporate their suggestions and respond to market changes swiftly (Malhotra et al., 2005). Information systems also provide formal and standard infrastructure to store, search and retrieve knowledge, enabling a manufacturer to set up routines and reuse technologies and components across different product lines or generations which reduce the costs and lead times for product innovation (Alavi and Leidner, 2001, Liu et al., 2013).

Information systems provide a platform for employees to analyse and transform knowledge collectively, share knowledge among each other and apply prior knowledge in decision making, enhancing AC (Francalanci and Morabito, 2008, Setia and Patel, 2013). However, information technologies alone cannot yield new products. It is the new knowledge about customer preferences and product ideas that leads to product innovation (Hargadon and Sutton, 1997, Zacharia et al., 2011). AC facilitates a manufacturer to learn changes in customer requirements and the specifics of the inputs and outputs of existing products (Lane et al., 2006, Todorova and Durisin, 2007), which are critical for new product development. In particular, acquisition helps a manufacturer obtain feedback on quality and design features of current products (Hult et al., 2004). A manufacturer can also gain knowledge about competitors' products, product improvement suggestions and technology and market development trends from customers and suppliers through acquisition (Lawson and Potter, 2012). Assimilation enables employees to combine and integrate such knowledge with existing knowledge (Nonaka, 1994), and hence employees can continually renew their knowledge stock and develop new applications of existing knowledge (Lane et al., 2006). Application helps employees implement new knowledge 
and suggestions obtained from both external and internal stakeholders to design new products (Zhang et al., 2015). Hence, the AC components jointly enable a manufacturer to take advantage of existing knowledge and develop new knowledge, enhancing product innovation. Therefore, the following hypothesis is proposed.

\section{H2: AC mediates information systems' effect on product innovation.}

Trust improves AC by promoting social interactions among employees (Zahra and George, 2002). Information systems can increase the effectiveness of the interactions. For example, network-based collaboration software and applications enable employees at different locations to have real-time formal or informal interactions to discuss and exchange knowledge, reducing the barriers that constrain the effectiveness of trust (Alavi and Leidner, 2001, Setia and Patel, 2013). Integrated knowledge management systems allow a manufacturer to keep and externalise the knowledge created through social interactions, improving the value of trust on AC (Nonaka, 1994, Roberts et al., 2012). Information systems improve $\mathrm{AC}$ by providing tools that facilitate the creation and distribution of knowledge (Liu et al., 2013). Trust among employees ensures that they are willing to use the tools to manage knowledge collectively (Mayer et al., 1995). Trust also motivates employees in different departments to work in teams to learn and internalise the knowledge provided by information systems (Nonaka, 1994, Hotho et al., 2012), increasing the value of information systems on AC. Hence, trust and information systems enhance each other's positive impact on AC. Therefore, the following hypothesis is proposed.

\section{H3: Trust and information systems are complementary in improving AC.}

Trust among employees plays a critical role in stimulating favourable attitudes and actions and increasing openness and tolerance for failures within a manufacturer (Yeung et al., 2009). Employees are thus more willing to work together and share their personal 
and privileged know-how and experiences without worrying that they will be taken advantage of by others (Mayer et al., 1995, Zahra and George, 2002). Commercialising tacit knowledge requires intensive social interactions and collaboration among employees (Hotho et al., 2012). Trust provides a social system that motivates employees to engage in knowledge exploitation and take potential risks associated with exploring novel and creative ideas even when outcomes are unpredictable (Nahapiet and Ghoshal, 1998, Katila and Ahuja, 2002). It can also tackle the barriers, such as the differences in goals, values and backgrounds among employees, when absorbing knowledge for product innovation (Adler and Kwon, 2002, Yeung et al., 2009). Trust among marketing, production and R\&D employees thus provides a social system that improves the effectiveness and timeliness of knowledge absorption (Adler and Kwon, 2002, Wang et al., 2011). AC enhances product innovation by providing knowledge inputs and trust can improve the value of the knowledge, thus enhancing AC's positive effect on product innovation. Therefore, the following hypothesis is proposed.

\section{H4: Trust enhances AC's effect on product innovation.}

Implementing explicit knowledge requires formal and systematic processes and tools (Nonaka, 1994). Information systems can automatically acquire information using standard formats and routines, process a large amount of information quickly and assist employees in making product development decisions, which help a manufacturer effectively and efficiently explore and exploit knowledge (Katila and Ahuja, 2002, Roberts et al., 2012). Information systems also provide a technical system that facilitates a manufacturer to develop a repository or an integrated database to keep best practices and knowledge and skills learned from past activities and events (Iyengar et al., 2015). They enable employees to apply existing knowledge to absorb new knowledge and reuse past experiences creatively to develop new products, enhancing the value of existing 
knowledge (Alavi and Leidner, 2001, Hult et al., 2004). Employees can also access, retrieve and use relevant information easily when designing new products (Tu et al., 2006). Hence, employees can cooperate on knowledge commercilisation and incorporate newly absorbed knowledge when making new product development decisions, improving the speed, quantity and quality of product innovation (Hargadon and Sutton, 1997, Kim et al., 2012). Information systems thus increase the value of the knowledge created by AC (Roberts et al., 2012), enhancing AC's positive effect on product innovation. Therefore, the following hypothesis is proposed.

H5: Information systems enhance AC's effect on product innovation.

\section{Research method}

\subsection{Questionnaire design}

Based on the relevant literature, a survey instrument was designed to measure a manufacturer's AC, product innovation, trust among employees and information systems. A multiple-item, 7-point Likert-type scale (1= "strongly disagree"; 7= "strongly agree") was used for all constructs. In addition, the questionnaire included questions related to the demographic profile of the manufacturers (e.g. industry, ownership and size), R\&D collaboration with university and competitor and number of long-term suppliers and customers. The scales are listed in the appendix.

$\mathrm{AC}$ was measured by acquisition, assimilation and application (Cohen and Levinthal, 1990, Lane et al., 2006, Todorova and Durisin, 2007). In particular, acquisition was measured by four items related to the routines and procedures for interacting with customers and suppliers (Zhang et al., 2015). They were developed based on the studies by Jansen et al. (2005) and Hult et al. (2004) and were adapted to the supply chain context. Assimilation was measured by four items related to the mechanisms and processes used 
to analyse, convert and distribute knowledge within a manufacturer (Todorova and Durisin, 2007). Two items gauging group learning and knowledge distribution were adapted from Jansen et al. (2005) and two new items on problem solving and training were added based on Zahra and George (2002). Application was measured by four items related to the routines and capabilities of incorporating knowledge into operations (Cohen and Levinthal, 1990). One item about knowledge exploitation was adapted from Jansen et al. (2005). Three new items related to making improvement suggestions, discovering new opportunities and reviewing long-term forecasting based on new knowledge were developed based on Zahra and George (2002).

Product innovation was measured by four items regarding both radical and incremental innovation (Ritala and Hurmelinna-Laukkanen, 2013). They were developed based on the studies by Damanpour (2010) and Kim et al. (2012). Trust was measured by three items about the relationships among the employees in marketing, $R \& D$ and production departments (Mayer et al., 1995, Yeung et al., 2009). Four items capturing outside-in information systems, internal knowledge management systems and network applications were used to measure information systems. They were developed based on the studies by Roberts et al. (2012) and Alavi and Leidner (2001).

We included six control variables that may influence product innovation and AC in the analyses. Large manufacturers are more likely to innovate and have higher levels of AC because they have more financial and technical capabilities and specialised personnel dedicated to innovation and knowledge management, and due to the economies of scale and scope to spread the risk of failure and the costs of innovation and knowledge creation (Damanpour, 2010). Firm size was measured by the number of employees (Un et al., 2010, Wang et al., 2011). Product innovation and AC can also be influenced by industry-wide factors, such as technological infrastructure, demand patterns, competition intensity and 
clock speed (Mazzola et al., 2015a). Three dummy variables were used to measure the four industries. In addition, researchers argue that $R \& D$ collaboration with university/competitor may influence product innovation and $\mathrm{AC}$ because they can provide a manufacturer additional resources and knowledge (Un et al., 2010, Mazzola et al., 2015a). Hence, we controlled R\&D collaboration with university/competitor which were measured using four items about the degree of and resource investments in $R \& D$ collaborations. Moreover, we controlled the number of long-term suppliers/customers (i.e. the suppliers/customers that have collaborated with a manufacturer for more than 3 years) because the more supply chain relations the more a manufacturer develops routines that can increase AC (Mazzola et al., 2015b). The natural logarithm of the number of longterm suppliers/customers was used in analyses.

The questionnaire was first developed in English and subsequently translated into Chinese by a professor. The Chinese version was then translated back into English by another professor. This translated English version was then checked against the original English version for any discrepancies and adjustments were made to reflect the original meaning of the questions in English. The questionnaire was pilot tested using a sample of 13 manufacturers before its full-scale launch. The research team discussed the questions face-to-face with managers after they filled out the questionnaire and clarified the meaning of the questions with them. When any confusion arose, the wording of the questions was modified.

\subsection{Sampling and data collection}

To test the hypotheses, manufacturing firms were randomly selected from four industries (i.e. textile and apparel, electrical appliances, electronics and communication equipment and automobile) in four major areas (i.e. Pearl River Delta, Yangtze River Delta, Bohai Sea Economic Area and Central China) that represent the national economy 
of China. The database provided by CSMAR Solution (http://csmar.gtadata.com/) was used as the sampling frame.

China provides an interesting testbed for the hypotheses. Due to the increasing labour and land costs, the cheap China is ending and Chinese manufacturers are competing through product innovation (Zhang et al., 2016). However, China has an underdeveloped legal system to provide sufficient protection for manufacturers' intellectual property rights and the enforcement of law is also problematic (Wang et al., 2011). Hence, Chinese manufacturers tend to develop new products by localizing and adapting existing technologies and products to Chinese markets (Zhang et al., 2016). Such creative adaptation is driven by the knowledge about supply chains and local markets and a manufacturer's AC. In addition, Chinese culture is characterized by collectivism and long-term orientation (Yeung et al., 2009). Trust among employees thus plays a very important role in facilitating collaborative knowledge creation and new product development. Moreover, along with the economic development, information and communication technology infrastructure has been evolving rapidly in China and network-based information systems have also been widely implemented by Chinese manufacturers.

After pilot-testing the questionnaire, it was decided to use one key informant who was knowledgeable on knowledge management routines and processes and was familiar with new product development, production processes and supply chain management. Potential key informants included supply chain managers, production managers, R\&D managers, presidents, senior executives and directors. Questionnaires were sent to 1,460 randomly selected manufacturers, but 133 of them were returned unopened. The research team finally collected 276 usable questionnaires. Hence, the response rate is $20.8 \%$. The sample demographics are shown in Table 1. 
Table 1 about here

Since the survey data was obtained from single informants, common method variance $(\mathrm{CMV})$ might be a concern. Several steps have been taken to control CMV. In particular, we provided a clear guideline and a glossary of terms at the end of the survey and arranged the order of the scale items randomly. We also prequalified potential respondents to ensure the informants were mid and senior level managers with high levels of relevant knowledge and assured the informants their responses would be kept anonymous. In addition, this study used multiple items for each construct, which alleviates concerns for $\mathrm{CMV}$, since potential biases tend to be more problematic at the item level than the construct level. Following Podsakoff et al. (2003), Harman's single factor test was performed on the acquisition, assimilation, application, product innovation, trust, information system, R\&D collaboration with university and R\&D collaboration with competitor variables using exploratory factor analysis. The results show 8 distinct factors with eigenvalues above or near 1.0 , explaining $68.72 \%$ of the total variance. Moreover, the first factor doesn't explain most the total variance, which is acceptable for this study where the constructs are correlated, both conceptually and empirically. To further assess CMV, confirmatory factor analysis (CFA) was also applied to perform the Harman's single factor test. The model fit indices are $\chi^{2}(434)=3321.583, \chi^{2} / \mathrm{df}=7.653$, Comparative Fit Index $(\mathrm{CFI})=0.460$, Tucker Lewis Index $(\mathrm{TLI})=0.421$, Root Mean Square Error of Approximation $($ RMSEA) $=0.156$ and Standardized Root Mean Square Residual $($ SRMR $)=0.134$, which are unacceptable $(\mathrm{Hu}$ and Bentler, 1999). The results suggest that no single or general factor emerges. As a third test of CMV, controlling for the effects of an unmeasured latent methods factor technique was used (Podsakoff et al., 2003). In particular, one measurement model including only the traits and one including a latent CMV factor in addition to the traits (i.e. items were allowed to load on their 
theoretical constructs as well as on the latent CMV factor) were tested (Podsakoff et al., 2003). The model fit indices of the second model improve marginally. The path coefficients of the trait factors and their significance levels are similar between the two models, suggesting that they are robust, despite the inclusion of the latent CMV factor. Therefore, CMV is not a significant threat in this study.

\subsection{Reliability and validity}

Reliability was assessed in terms of composite reliability and Cronbach's Alpha (Fornell and Larcker, 1981). The values of composite reliability and Cronbach's Alpha range from 0.830 to 0.951 and from 0.734 to 0.923 respectively (appendix), which are all above the recommended threshold value of 0.70 , suggesting adequate reliability.

Convergent validity was assessed by the average variance extracted (AVE). The appendix shows that all of the AVE values are above the recommended value of 0.50 (ranging from 0.551 to 0.866 ), which demonstrate adequate convergent validity (Fornell and Larcker, 1981). A measurement model was constructed using CFA to further assess convergent validity. In the model, the items for $\mathrm{AC}$ were linked first to the constructs of acquisition, assimilation and application, which then loaded onto the AC construct, and the items for trust, information system, product innovation, R\&D collaboration with university and R\&D collaboration with competitor were directly linked to corresponding constructs. The covariance among the constructs was freely estimated. The resulting model fit indices are $\chi^{2}(416)=862.963, \chi^{2} / \mathrm{df}=2.074, \quad$ CFI $=0.916, \quad$ TLI $=0.907$, RMSEA $=0.063$ and $S R M R=0.057$, which are better than the threshold values recommended by $\mathrm{Hu}$ and Bentler (1999). The factor loadings range from 0.584 to 0.958 and the t-statistics of the factor loadings are all significant at the $\mathrm{p}<0.01$ level (appendix). Therefore, convergent validity is achieved (Fornell and Larcker, 1981). 
Discriminant validity was assessed by comparing the square roots of the AVE of each construct with the correlations between the focal construct and each other construct. A square root higher than the correlations with other constructs suggests discriminant validity (Fornell and Larcker, 1981). Table 2 shows the mean and standard deviation of the constructs and their correlations. Comparisons of all the correlations and square roots of the AVEs on the diagonal indicate adequate discriminant validity for all constructs. Discriminant validity was further assessed by using constrained measurement models for each possible pair of constructs in which the correlation between this pair of constructs was fixed to 1 . The constrained measurement models were subsequently compared to the original unconstrained measurement model in which the correlations among constructs were freely estimated. In this study, all the $\chi^{2}$ differences between the constrained and unconstrained models are significant at the 0.01 level. As such, discriminant validity is achieved (Fornell and Larcker, 1981).

Table 2 about here

\section{Analysis and results}

Hierarchical regression and bootstrapping methods are used to test the hypotheses. To mitigate the potential threat of multi-collinearity, the variables are mean-centred prior to the formation of interaction terms, as recommended by Aiken and West (1991). Furthermore, we calculate variance inflation factors (VIFs) in each of the regression equations. The maximum VIF within the models is 2.37 , which is well below the rule-ofthumb cut-off of 10 (Aiken and West, 1991).

Baron and Kenny (1986)'s method is used to test the mediating role of AC and the results are presented in Table 3. AC is used as the dependent variable in Model 1. The result shows that trust $(b=0.287, \mathrm{p}<0.001)$ and information systems $(b=0.544, \mathrm{p}<0.001)$ 
have significant effects on $\mathrm{AC}$, indicating that the independent variables (i.e. trust and information systems) significantly influence the mediator (i.e. AC). Then, the interaction between trust and information systems is entered in Model 2 and the result shows that it $(b=0.211, \mathrm{p}<0.01)$ positively affects AC. Therefore, trust and information systems are complementary in improving AC, supporting H3. Product innovation is used as the dependent variable in Model 3 and 4. Model 3 reveals that trust $(b=0.230, \mathrm{p}<0.001)$ and information systems $(b=0.300, \mathrm{p}<0.001)$ have significant effects on product innovation, indicating that the independent variables significantly influence the dependent variable (i.e. product innovation). Then, we add $\mathrm{AC}$ in Model 4, the result shows that $\mathrm{AC}(b=$ $0.262, \mathrm{p}<0.01$ ) has a significant effect on product innovation. However, the effects of trust and information systems become non-significant, indicating that including the mediator in the model reduces the effects of the independent variables to non-significance. We also examine the indirect effects of trust and information systems on product innovation through AC using the bias-corrected bootstrapping method with a $95 \%$ confidence level and 5000 samples (Preacher and Hayes, 2008). The results show that the indirect effect of trust on product innovation through $\mathrm{AC}$ is 0.183 and the biascorrected $95 \%$ confidence interval of the indirect effect is $(0.119,0.255)$. The indirect effect of information systems on product innovation is 0.243 and the bias-corrected $95 \%$ confidence interval of the indirect effect is $(0.124,0.358)$. Hence, the findings suggest that AC fully mediates the effects of trust and information systems on product innovation, supporting $\mathrm{H} 1$ and $\mathrm{H} 2$.

Table 3 about here

The moderating effects of trust and information systems are tested by examining the interactions between the independent variable (i.e. AC) and moderators (i.e. trust and 
information systems) (Baron and Kenny, 1986) and the results are presented in Table 4. Product innovation is used as the dependent variable in all three models. Model 1 includes the control, independent and moderator variables. The result demonstrates that $\mathrm{AC}(b=$ 0.262, $\mathrm{p}<0.01$ ) significantly influences product innovation. Then, the interactions between $\mathrm{AC}$ and trust and between $\mathrm{AC}$ and information systems are entered in Model 2 and 3, respectively. We find that the interaction between $\mathrm{AC}$ and trust $(b=0.138, \mathrm{p}<0.05)$ and the interaction between $\mathrm{AC}$ and information systems $(b=0.224, \mathrm{p}<0.001)$ significantly affect product innovation, indicating that trust and information systems positively moderate the effect of AC on product innovation (Baron and Kenny, 1986).

Table 4 about here

Because the effects of trust and information systems on product innovation are mediated by AC, we test the moderated mediation effects using the bootstrapping method (Preacher et al., 2007). The moderators (i.e. trust and information systems) are set at three different values (i.e. mean and \pm 1 standard deviation) and then the indirect effects of trust and information systems on product innovation through AC are estimated using the biascorrected bootstrapping method with a 95\% confidence level and 5000 samples (Preacher et al., 2007). The bias-corrected $95 \%$ confidence intervals when the trust values are set at mean (5.612), one standard deviation above the mean (6.780) and one standard deviation below the mean $(4.444)$ are $(0.124,0.258),(0.154,0.351)$ and $(0.054,0.235)$ respectively. The bias-corrected $95 \%$ confidence intervals when the information systems values are set at mean (5.495), one standard deviation above the mean (6.528) and one standard deviation below the mean $(4.462)$ are $(0.138,0.364),(0.218,0.501)$ and $(0.020$, 0.274) respectively. All these confidence intervals are positive and different from zero, suggesting that trust and information systems moderate the impact of $\mathrm{AC}$ on product 
innovation after accounting for the relationships between trust and information systems and AC (Preacher et al., 2007). Therefore, H4 and H5 are supported.

\section{Discussion and conclusions}

\subsection{Theoretical contributions}

This study contributes to operations management literature in three ways. First, the findings provide empirical evidence that trust and information systems enhance AC's effect on product innovation. Researchers find that AC facilitates knowledge transfer and innovation (Lawson and Potter, 2012, Nagati and Rebolledo, 2012, Tavani et al., 2014). Empirical evidence also exists that AC's effects are moderated by environmental conditions (Setia and Patel, 2013, Saenz et al., 2014) and supply chain partner's capabilities (Whitehead et al., 2016). This study further reveals that a manufacturer's sociotechnical systems moderate the relationship between AC and product innovation, enhancing current understandings on the contingencies that influence AC's effects and how to fully reap AC's benefits on new product development (Volberda et al., 2010, Lawson and Potter, 2012). By building a moderated mediation model, we link AC and product innovation with trust and information systems, providing insights into how to design organisational systems to enhance the effectiveness of knowledge management processes (Hult et al., 2006). In addition, this study adopts a capability view of AC and explicitly captures the acquisition, assimilation and application processes (Lane et al., 2006, Roberts et al., 2012). The findings enrich existing knowledge on how to design knowledge management processes to absorb and leverage knowledge for new product development (Tavani et al., 2014, Whitehead et al., 2016).

Second, this study provides empirical evidence that trust and information systems improve AC both individually and interactively, extending current understandings on the 
antecedents of AC (Marabelli and Newell, 2014). The majority of existing empirical studies focus on the effects of either socialisation (Zahra and George, 2002, Jansen et al., 2005) or information technology (Roberts et al., 2012, Setia and Patel, 2013) capabilities on AC development. We take an integrative view on a manufacturer's sociotechnical systems and simultaneously investigate the effects of trust among employees and information systems on AC. The findings reveal that trust and information systems are complementary in improving AC, highlighting the importance of co-designing social and technical systems in developing AC (Lane et al., 2006, Volberda et al., 2010). The results also provide a holistic picture on the complex relationships between an organisation's sociotechnical systems and knowledge management processes.

Third, this study finds that AC mediates the effects of trust and information systems on product innovation, providing insights into how to fully capitalise the relationships among employees and information technologies for new product development (Calantone et al., 2002, Swink and Song, 2007, Roberts et al., 2012). The results show that both trust and information systems improve new product development indirectly through AC which enhances current understandings of how trust, information systems and $\mathrm{AC}$ interact to affect product innovation (Hotho et al., 2012, Saenz et al., 2014, Marabelli and Newell, 2014). This study also reveals that a moderated mediation relationship exists among a manufacturer's sociotechnical systems, AC and product innovation, suggesting that a manufacturer should jointly design its organisational systems and knowledge management processes to support new product development (Lane et al., 2006, Mazzola et al., 2015b).

\subsection{Managerial implications}

This study provides guidelines that help operations managers understand knowledge management better and how to design organisational systems to develop AC and reap the 
benefits of $\mathrm{AC}$ on new product development. The findings reveal that $\mathrm{AC}$ can help manufacturers develop new products and highlight the need for managers to develop knowledge management processes that include both external-facing and internal components. Hence, we suggest managers organise focus groups and brainstorming sessions with customers and suppliers. Standard operating procedures should be developed to guide employee's interactions with customers and suppliers, such as presale and after-sale visits and supplier evaluation and auditing. In addition, managers must be aware that building routines and procedures for acquiring knowledge alone is not enough. Manufacturers who want to take full advantage of the knowledge residing in supply chains on new product development should invest in internal processes that emphasise knowledge assimilation and application at the same time. For example, learning groups and problem solving teams that involve representatives from multiple functions should be formed to share information, discuss improvement suggestions and coordinate decisions. Managers should design training programs to improve employees' information processing skills and distribute existing knowledge and past successful experiences to them. Executive meetings should be held regularly to discuss new business opportunities and review long-term forecasting about market and technology development trends to provide strategic guidelines for product innovation.

This study reveals that trust among employees and information systems improve product innovation indirectly through AC and enhance AC's effect on product innovation. They also have both individual and interactive effects on AC. The findings indicate that $\mathrm{AC}^{\prime}$ effects are contingent upon the sociotechnical systems of a manufacturer. Hence, a manufacturer may not be able to gain full advantage of $\mathrm{AC}$ on new product development without investments in organisational systems. Managers should pay attention to the design of sociotechnical systems to support knowledge management and new product 
development, given their important effects in maximising the potential value of AC and the synergies between $\mathrm{AC}$ and trust and information systems. Therefore, we suggest manufacturers invest in formal and informal arrangements to build trust among employees and develop network-based information and knowledge management systems at the same time. In particular, managers should empower employees to interact with colleagues across functional boundaries and build horizontal channels for crossfunctional collaboration. Social events, such as conferences, workshops and parties, should be organised to help employees interact with each other. Providing feedback about successful product development projects can help employees develop positive expectations about colleagues' goodwill and competence. Manufacturers should also invest in information technologies such as enterprise resource planning systems, integrated databases and collaboration software and applications, and motivate employees to use these tools to process and implement knowledge collaboratively. Managers should develop rules and regulations about how knowledge, such as results of group discussion, employee suggestions, successful product development experiences and lessons learned from product failures, is codified, stored and retrieved using information systems. Regular training programs and manuals regarding how to use information systems should be provided to employees.

\subsection{Limitations and future research directions}

While this study makes significant theoretical and practical contributions, it has limitations that open up avenues for future research. First, we conduct this study in China. The relationships among trust, information systems, AC and product innovation might be influenced by the Chinese business, cultural and institutional environments. Future research could examine the research model in other countries to generalise the findings. Second, this study tests the research model using cross-sectional data. Researchers argue 
that innovation may influence AC (Cohen and Levinthal, 1990) and an orgranisational environment promoting innovation may improve trust among employees (Adler and Kwon, 2002). Future research could extend the study by using a longitudinal design to investigate the evolution and dynamics among trust, AC and innovation. Third, this study may have the problem of endogeneity because some uncontrolled confounders may cause both independent and dependent variables of the model, which is a limitation. Fourth, researchers argue that relational embeddedness in an innovation network positively influences AC (Mazzola et al., 2015b). Exploring the impact of supply chain relationship on the linkage between $\mathrm{AC}$ and new product development is an interesting topic. Fifth, this study focuses on both incremental and radical product innovation. Researchers argue that incremental and radical innovation is associated with exploitative and exploratory learning respectively (Hargadon and Sutton, 1997, Katila and Ahuja, 2002) and a firm's AC may employ different levels of exploitation and exploration (Lane et al., 2006). Future studies could investigate how different types of AC influence incremental and radical innovation. Sixth, this study does not consider internal R\&D investments, which is a limitation (Cohen and Levinthal, 1990). Future studies could examine the impacts of internal R\&D investments on acquisition, assimilation and application processes.

\section{References}

Adler, P. S. and Kwon, S. (2002), "Social capital: Prospects for a new concept". Academy of Management Review, Vol. 27, No. 1, pp.17-40.

Alavi, M. and Leidner, D. E. (2001), "Review: Knowledge management and knowledge management systems: Conceptual foundations and reseearch issues". MIS Quarterly, Vol. 25, No. 1, pp.107-136. 
Aiken, L. S. and West, S. G. (1991), Multiple regression: Testing and interpreting interactions, Sage Publishing, Thousand Oaks.

Baron, R. M. and Kenny, D. A. (1986), "The moderator-mediator variable distinction in social psychological research: Conceptual, strategic, and statistical considerations". Journal of Personality and Social Psychology, Vol. 51, No. 6, pp.1173-1182.

Calantone, R., Droge, C. and Vickery, S. (2002), "Investigating the manufacturingmarketing interface in new product development: Does context affect the strength of relationships?" Journal of Operations Management, Vol. 20, No. 3, pp.273287.

Cepeda-Carrion, G., Cegarra-Navarro, J. G. and Jimenez-Jimenez, D. (2012), "The effect of absorptive capacity on innovativeness: Context and information systems capability as catalysts". British Journal of Management, Vol. 23, No. 1, pp.110129.

Cohen, W. M. and Levinthal, D. A. (1990), "Absorptive capacity: A new perspective on learning and innovation". Administrative Science Quarterly, Vol. 35, No. 1, pp.128-152.

Damanpour, F. (2010), "An integration of research findings of effects of firm size and market competition on product and process innovations". British Journal of Management, Vol. 21, No. 4, pp.996-1010.

Enkel, E., Heil, S., Hengstler, M., and Wirth, H. (2017), "Exploratory and exploitative innovation: To what extent do the dimensions of individual level absorptive capacity contribute?" Technovation, Vol.60/61, pp.29-38. 
Fornell, C. and Larcker, D. F. (1981), "Evaluating structural equation models with unobservable variables and measurement errors". Journal of Marketing Research, Vol. 18, No. 1, pp.39-50.

Francalanci, C. and Morabito, V. (2008), "IS integration and business performance: The mediation effect of organizational absorptive capacity in SMEs". Journal of Information Technology, Vol. 23, No.4, pp.297-312.

Hargadon, A. and Sutton, R. I. (1997), "Technology brokering and innovation in a product development firm". Administrative Science Quarterly, Vol. 42, No. 4, pp.716-749.

Hargadon, A. and Sutton, R. I. (2000), "Building an innovation factory". Harvard Business Review, Vol. 78, No. 3, pp.157-166.

Hotho, J.J., Becker-Ritterspach, F., and Saka-Helmhout, A. (2012), "Enriching absorptive capacity through social interaction". British Journal of Management, Vol. 23, No.3, pp.383-401.

Hu, L. and Bentler, P. M. (1999), "Cutoff criteria for fit indices in covariance structure analysis: Conventional criteria versus new alternatives". Structural Equation Modeling, Vol. 6, No. 1, pp.1-55.

Huber, V. L. and Brown, K.A. (1991), "Human resource issues in cellular manufacturing: A sociotechnical analysis". Journal of Operations Management, Vol. 10, No.1, pp.138-159.

Hult, G. T. M., Ketchen, J. D. J., Cavusgil, S. T. and Calantone, R. J. (2006), "Knowledge as a strategic resource in supply chains". Journal of Operations Management, Vol. 24, No. 5, pp.458-475.

Hult, G. T. M., Ketchen Jr., D. J. and Slater, S. F. (2004), "Information processing, knowledge development, and strategic supply chain performance". Academy of Management Journal, Vol. 47, No. 2, pp.241-253. 
Iyengar, K., Sweeney, J.R., and Montealegre, R. (2015), "Information technology use as a learning mechanism: The impact of IT ues on knowledge transfer effectivenss, absorptive capacity, and franchisee performance". MIS Quarterly, Vol.39, No3, pp. 615-641.

Jansen, J. J. P., van den Bosch, F. A. J. and Volberda, H. W. (2005), "Managing potential and realized absorptive capacity: How do organizational antecedents matter?" Academy of Management Journal, Vol. 48, No. 6, pp.999-1015.

Kauppi, K., Brandon-Jones, A., Ronchi, S., and van Raaij, E.M. (2013), "Tools without skills: Exploring the moderating effect of absorptive capacity on the relationship between E-purchasing tools and category performance." International Journal of Operations \& Production Management, Vol.33, No.7, pp.828-857.

Katila, R., and Ahuja, G. (2002), "Something old, something new: A longitudinal study of search behavior and new product development." Academy of Management Journal, Vol. 45, No.6, pp. 1153-1194.

Kim, D., Kumar, V. and Kumar, U. (2012), "Relationship between quality management practices and innovation". Journal of Operations Management, Vol. 30, No. 4, pp.295-315.

Lane, P. J., Koka, B. R. and Pathak, S. (2006), "The reification of absorptive capacity: A critical review and rejuvenation of the construct". Academy of Management Review, Vol. 31, No. 4, pp.833-863.

Lawson, B., and Potter, A. (2012), "Determinants of knoweldge transfer in inter-firm new product development projects". International Journal of Operations \& Production Management, Vol.32, No.10, pp.1228-1247. 
Liu, H., Ke, W., Wei, K.K., and Hua, Z. (2013), "The impact of IT capabilities on firm performance: The mediating roles of absorptive capacity and supply chain agility". Decision Support Systems, Vol. 54, No.3, pp.1452-1462.

Malhotra, A., Gosain, S. and El Sawy, O.A. (2005), "Absorptive capacity configurations in supply chains: Gearing for parnter enabled market knowledge creation". MIS Quarterly, Vol. 29, No. 1, pp.145-187.

Marabelli, M. and Newell, S. (2014), "Knowing, power and materiality: A critical review and reconceptulizatoin of absorptive capacity". International Journal of Management Reviews, Vol.16, No.4, pp.479-499.

Mayer, R. C., Davis, J. H. and Schoorman, F. D. (1995), "An integrative model of organizational trust". Academy of Management Review, Vol. 20, No. 3, pp.709734.

Mazzola, E., Perrone, G., and Kamuriwo, D.S. (2015a), "Network embeddedness and new product development in the biopharmaceutical industry: The moderating role of open innovation flow". International Journal of Production Economics, Vol. 160, pp.106-119.

Mazzola, E., Bruccoleri, M., and Perrone, G. (2015b), "Supply chain of innovation and new product development." Journal of Purchasing \& Supply Management, Vol. 21, pp. 273-284.

Nagati, H. and Rebolledo, C. (2012), "The role of relative absorptive capacity in improving suppliers' operational performance". International Journal of Operations \& Production Management, Vol. 32 No. 5, pp. 611-630.

Nahapiet, J. and Ghoshal, S. (1998), "Social capital, intellectual capital, and the organizational advantage". Academy of Management Review, Vol. 23, No. 2, pp.242-266. 
Nonaka, I. (1994), "A dynamic theory of organizational knowledge creation". Organization Science, Vol. 5, No. 1, pp.14-37.

Patel, P. C., Terjesen, S. and Li, D. (2012), "Enhancing effects of manufacturing flexibility through operational absorptive capacity and operational ambidexterity". Journal of Operations Management, Vol. 30, No. 3, pp.201-220.

Pasmore, W.A. (1988), Designing effective organizations: The sociotechnical systems perspective. John Wiley \& Sons, New York.

Podsakoff, P. M., Mackenzie, S. B., Lee, J. Y. and Podsakoff, N. P. (2003), "Common method biases in behavioral research: A critical review of the literature and recommended remedies". Journal of Applied Psychology, Vol. 88, No. 5, pp.879903.

Preacher, K., Rucker, D. D., and Hayes, A. F. (2007), "Addressing moderated mediation hypotheses: Theory, methods, and prescriptions". Multivariate Behavioural Research, Vol.42, No. 1, pp.185-227.

Preacher, K. and Hayes A. (2008), "Asymptotic and resampling strategies for assessing and comparing indirect effects in multiple mediator models". Behavior Research Methods, Vol.40, No.3, pp.879-891.

Ritala, P. and Hurmelinna-Laukkanen, P. (2013), "Incremental and radical innovation in coopetition - the role of absorptive capacity and appropriability". Journal of Product Innovation Management, Vol. 30, No. 1, pp.154-169.

Roberts, N., Galluch, P. S., Dinger, M. and Grover, V. (2012), "Absorptive capacity and information systems research: Revew, synthesis, and directions for future research". MIS Quarterly, Vol. 36, No. 2, pp.625-648. 
Sanez, M.J., Revilla, E., and Knoppen, D. (2014), "Absorptive capacity in buyer-supplier relationships: Empirical evidence of its mediating role". Journal of Supply Chain Management, Vol.50, No.2, pp.18-40.

Setia, P. and Patel, P. C. (2013), "How information systems help create OM capabilities: Consequents and antecedents of operational absorptive capacity". Journal of Operations Management, Vol. 31, No. 6, pp.409-431.

Swink, M. and Song, M. (2007), "Effects of marketing-manufacturing integration on new product development time and competitive advantage". Journal of Operations Management, Vol. 25, No. 1, pp.203-217.

Tavani, S.N., Sharifi, H. and Ismail, H.S. (2014), "A study of contingency relationships between supplier involvement, absorptive capacity and agile product innovation". International Journal of Operations \& Production Management, Vol.34, No.1, pp. 65-92.

Todorova, G. and Durisin, B. (2007), "Absorptive capacity: Valuing a reconceptulization". Academy of Management Review, Vol. 32, No. 3, pp.774-786.

Tu, Q., Vonderembse, M. A., Ragu-Nathan, T. S. and Sharkey, T. W. (2006), "Absorptive capacity: Enhancing the assimilation of time-based manufacturing practices". Journal of Operations Management, Vol. 24, No. 5, pp.692-710.

Un, C.A., Cuervo-Cazurra, A., and Asakawa, K. (2010), "R\&D collaborations and product innovation". Journal of Product Innovation Management, Vol.27, No.5, pp. 673-689.

Volberda, H. W., Foss, N. J. and Lyles, M. A. (2010), "Absorbing the concept of absorptive capacity: How to realize its potential in the organization field". Organization Science, Vol. 21, No. 4, pp.931-951. 
Wang, L., Yeung, J. H. Y. and Zhang, M. (2011), "The impact of trust and contract on innovation performance: The moderating role of environmental uncertainty". International Journal of Production Economics, Vol. 134, No. 1, pp.114-122.

Whitehead, K.K., Zacharia, Z.G., and Prater, E.L. (2016), "Absorptive capacity versus distributive capability: The asymmetry of knowledge transfer". International Journal of Operations \& Production Management, Vol.36, No.10, pp.1308-1332.

Yeung, J. H. Y., Selen, W., Zhang, M. and Huo, B. (2009), "The effects of trust and coercive power on supplier integration". International Journal of Production Economics, Vol. 120, No. 1, pp.66-78.

Zahra, S. A. and George, G. (2002), "Absorptive capacity: A review, reconceptualization, and extension". Academy of Management Review, Vol. 27, No. 2, pp.185-203.

Zhang, M., Zhao, X., Lyles, M. and Guo, H. (2015), "Absorptive capacity and mass customization capability". International Journal of Operations \& Production Management, Vol.35, No.9, pp.1275-1294.

Zacharia, Z.G., Nix, N.W., and Lusch, R.F. (2011), "Capabilities that enhance outcomes of an episodic supply chain collaboration". Journal of Operations Management, Vol.29, No.6, pp.591-603.

Zhang, M., Zhao, X., Voss, C. and Zhu, G. (2016), "Innovating through services, cocreation and supplier integration: Cases from China". International Journal of Production Economics, Vol.171, pp.289-300.

Appendix Measurement items

\begin{tabular}{|l|l|}
\hline & Loading $^{++}$ \\
\hline Absorptive capacity & .892 \\
\hline Acquisition C.R. $=0.879$ alpha $=0.816 \mathrm{AVE}=0.644^{+}$ & .725 \\
\hline $\begin{array}{l}\text { We periodically organize special meetings with customers (e.g. focus } \\
\text { groups and brainstorming sessions) to find out what products/services are } \\
\text { needed in the future. }\end{array}$ & \\
\hline
\end{tabular}




\begin{tabular}{|c|c|}
\hline $\begin{array}{l}\text { We have formal routines and standard operating procedures to guide } \\
\text { employees' interactions with customers. }\end{array}$ & .711 \\
\hline $\begin{array}{l}\text { We periodically organize special meetings with suppliers (e.g. focus groups } \\
\text { and brainstorming sessions) to find out what products/services are needed } \\
\text { in the future. }\end{array}$ & .741 \\
\hline $\begin{array}{l}\text { We have formal routines and standard operating procedures to guide } \\
\text { employees' interactions with suppliers. }\end{array}$ & .725 \\
\hline Assimilation C.R. $=0.911$ alpha $=0.870$ AVE $=0.720$ & .831 \\
\hline $\begin{array}{l}\text { We regularly organize learning groups to discuss the consequences of new } \\
\text { knowledge. }\end{array}$ & .780 \\
\hline $\begin{array}{l}\text { We have special mechanisms to solve conflict when employees have } \\
\text { different understandings and interpretations of new knowledge. }\end{array}$ & .764 \\
\hline $\begin{array}{l}\text { We have special procedures for employees to share knowledge and } \\
\text { practical experiences. }\end{array}$ & .839 \\
\hline $\begin{array}{l}\text { We have special training programs that help employees grasp new } \\
\text { knowledge. }\end{array}$ & .787 \\
\hline Application C.R. $=0.858$ alpha $=0.780$ AVE $=0.603$ & .944 \\
\hline $\begin{array}{l}\text { Our employees frequently make improvement suggestions (e.g. products } \\
\text { and processes) based on new knowledge. }\end{array}$ & .668 \\
\hline $\begin{array}{l}\text { We have systematic procedures for discovering new business opportunities } \\
\text { based on new knowledge. }\end{array}$ & .736 \\
\hline $\begin{array}{l}\text { We periodically review our long-term forecasting (e.g. market trends and } \\
\text { technology development) based on new knowledge. }\end{array}$ & .646 \\
\hline We constantly consider how to better exploit knowledge. & .698 \\
\hline \multicolumn{2}{|l|}{ Trust C.R. $=0.951$ alpha $=0.923$ AVE $=0.866$} \\
\hline The employees in production and R\&D departments trust each other. & .872 \\
\hline The employees in production and marketing departments trust each other. & .887 \\
\hline The employees in marketing and R\&D departments trust each other. & .924 \\
\hline \multicolumn{2}{|l|}{ Information system C.R. = 0.830 alpha=0.734 AVE= 0.551} \\
\hline $\begin{array}{l}\text { Our company uses network-based collaboration software and applications } \\
\text { (e.g. office automation). }\end{array}$ & .610 \\
\hline $\begin{array}{l}\text { Our company uses integrated knowledge management systems (e.g. } \\
\text { discussion forum and database). }\end{array}$ & .734 \\
\hline $\begin{array}{l}\text { We and our customers are connected by network-based information } \\
\text { systems. }\end{array}$ & .584 \\
\hline We and our suppliers are connected by network-based information systems. & .609 \\
\hline \multicolumn{2}{|l|}{ Product innovation C.R. $=0.921$ alpha $=0.886$ AVE $=0.745$} \\
\hline We can introduce new products quickly. & .831 \\
\hline We are highly capable of incremental product innovation. & .866 \\
\hline We are highly capable of radical product innovation. & .813 \\
\hline $\begin{array}{l}\text { We can design new products that differ substantially from our existing } \\
\text { products based on new technologies. }\end{array}$ & .746 \\
\hline \multicolumn{2}{|l|}{$\begin{array}{l}\text { R\&D collaboration with university } C . R .=0.944 \text { alpha=0.921 AVE= } \\
0.808\end{array}$} \\
\hline We frequently collaborate with universities on R\&D. & .786 \\
\hline $\begin{array}{l}\text { We have invested a lot of human resources to collaborate with universities } \\
\text { on R\&D. }\end{array}$ & .958 \\
\hline $\begin{array}{l}\text { We have invested a lot of financial resources to collaborate with } \\
\text { universities on R\&D. }\end{array}$ & .929 \\
\hline
\end{tabular}




\begin{tabular}{|l|l|}
\hline We collaborate with universities on many R\&D projects. & .772 \\
\hline $\begin{array}{l}\text { R\&D collaboration with competitor C.R. }=\mathbf{0 . 9 1 3} \text { alpha=0.871 AVE= } \\
\mathbf{0 . 7 2 4}\end{array}$ & \\
\hline We frequently collaborate with competitors on R\&D. & .632 \\
\hline $\begin{array}{l}\text { We have invested a lot of human resources to collaborate with competitors } \\
\text { on R\&D. }\end{array}$ & .890 \\
\hline $\begin{array}{l}\text { We have invested a lot of financial resources to collaborate with } \\
\text { competitors on R\&D. }\end{array}$ & .878 \\
\hline We collaborate with competitors on many R\&D projects. & .779 \\
\hline
\end{tabular}

Note $:{ }^{+} C . R .=$ composite reliability. alpha $=$ Cronbach's alpha. AVE=average variance extracted.

${ }^{++}$All item loadings are significant at the $p<0.01$ level ( $t$ values range from 9.115 to 22.067). 